\title{
Characterization of Beam-Induced Reactions Occurring in Liquid Secondary Ion Mass Spectrometry/Fast-Atom Bombardment by Tandem Mass Spectrometry
}

\author{
A. Agnello, E. De Pauw, and P. Natalis \\ Department of General and Physical Chemistry, University of Liege, Liege, Belgium
}

\begin{abstract}
A specific beam-induced secondary reaction involving the condensation of hydroxylic matrices with some organic groups (aldehydes, ketones, etc.) accompanied by the loss of a water molecule was investigated by liquid secondary ion mass spectrometry/fast-atom bombardment (LSIMS/FAB). A mechanistic scheme and a structure of the induced product are proposed. The features of this secondary reaction were studied and the influence of the types of solutes, acidic additives, and matrices analyzed. Rather than a drawback, LSIMS/FAB mass spectrometry can take advantage of this matrix effect to infer analytical information through tandem mass spectrometry experiments. Specific neutral loss scans can be conducted to highlight beam-induced reactive molecules, even when the detection of these species is prevented in normal scan spectra by other surface-active components. (J Am Soc Mass Spectrom 1993, 4, 312-321)
\end{abstract}

$\mathrm{T}$ The development of soft ionization methods has extended the scope of mass spectrometry to the analysis of involatile and thermally labile compounds. The wide use of secondary ion mass spectrometry (SIMS) and fast-atom bombardment (FAB) is essentially due to the introduction of a liquid matrix [1] that allows an increase in the primary flux $[2,3]$, raising at the same time the secondary ion current and cnabling tandem mass spectrometry (MS/MS) experiments to be performed. The high-intensity, longlasting sccondary signal reflects both quasimolecular and fragment ions and therefore offers significant structural information.

The main features of liquid matrices used in liquid SIMS (LSIMS)/FAB experiments have recently been reported [3]. Liquid matrices have the following effects on the spectral behavior of analytes: (1) They act as an energy buffer and mitigate the fragmentation of solute molecules [4]; and (2) they can give rise to acid base reactions between analyte and solvent and therefore promote the formation of protonated molecular ions [5] and raise the ionization yield. The latter task can also be performed by appropriate additives. The addition of surface-active acids (camphorsulfonic acid, p-toluenesulfonic acid) offers two major assets [6]:

Address reprint requests to A. Agnello, Department of General and Physical Chemistry, University of Liege B-6, Sart-Tilman, 4000 Liege, Belgium.
(1) They promote the formation of protonated molecular ions; and (2) they induce the surface migration of solute cations and accordingly improve the spectral quality because of the matrix background mitigation.

A common drawback in mixture analysis is the suppression occurring when a high surface-activity compourd is able to prevent other solutes from reaching the surface. The use of surface-active acid additives can mitigate this effect [7].

Matrix effects are well known in the literature and may bring severe drawbacks. For example, particlebeam-induced Schiff bases are formed from peptides and glycerol $[8,9]$. Halogenated nucleosides in glycerol undergo extensive dehalogenation during $\mathrm{FAB}$ experiments [10]. Abundant beam-induced adducts of $N$-alkylpyridinium salts are produced with glycerol [11]. Matrix effects are also observed with some coordination complexes [12-14]. Oxidation-reduction processes have also received considerable attention [15-18].

The liquid matrix can simply act as a solvation agent but, in some cases, it can react with analyte molecules and induce the formation of new chemical bonds [19]. This secondary effect may be beam induced or not.

The focus of this study is to point out a beaminduced process involving the condensation of hydroxylic solvents with some organic functional groups (aldehydes, ketones, etc.) with loss of a water molecule 
[20-22]. This reaction is compared with the acid-catalyzed classical solution reaction [23].

This study is divided into four parts and aims to answer the following questions: (1) What are the reaction mechanism(s) and structure(s) of the [solute + glycerol $\left.+\mathrm{H}-\mathrm{H}_{2} \mathrm{O}\right]^{+}$cluster? (2) How does acidity influence the condensation process? (3) Which kinds of analytes are able to undergo this secondary reaction? When the reaction conditions are better understood, a fourth question arises: (4) Can this matrix effect be analytically useful, taking advantage of the MS/MS technique?

\section{Experimental}

\section{Liquid Secondary Ion Mass Spectra}

Liquid secondary ion mass spectra were acquired with a VG Autospec-Q mass spectrometer (EBEQQ configuration) (VG, Manchester, UK). The LSIMS gun was operated at $16 \mathrm{kV}$, giving 8-keV cesium ions on the target. The emission current was kept at $2 \mu \mathrm{A}$. Spectra were acquired with a mass resolution of $2000(10 \%$ valley definition). Mass calibration was achieved using CsI. All functions of the Autospec-Q were controlled by the spectrometer input/output system (SIOS) interface and the OPUS data system. The relative intensities of the representative secondary ions were obtained from their current intensity versus time curve. These relative intensities were measured after $2 \mathrm{~min}$ of bombardment. The intensity sum of the [solute $+\mathrm{H}]^{+}$, [solute + matrix $+\mathrm{H}^{+}$, and [solute + matrix $+\mathrm{H}_{-}$ $\mathrm{H}_{2} \mathrm{Ol}^{+}$signals was taken as $100 \%$, except as otherwise noted.

Constant neutral loss linked scans were performed with the VG Autospec-Q in such a way as to detect metastable decomposition in the 1 free field region (FFR) with no collision gas [scan function: $B^{2}(1-$ $\left.E) / E^{2}\right]$. The gain was fixed at $2 \times 10^{5}$ for neutral loss experiments (relative to $10^{4}$ for normal scans). The precursor mass is labeled on the MS/MS neutral loss spectra.

Daughter ion spectra used for the determination of the acetal structure were recorded on a FinniganMAT (San Jose, CA) triple-stage quadrupole TSQ70. Collision-activated dissociation (CAD) was performed in the second quadrupole, which was operated as a focusing collision chamber in the radiofrequency (rf)only mode. Xenon was used as collision gas (approximate pressure 0.7 mtorr). The collision energy was kept in the $10-\mathrm{eV}$ range.

\section{Reagents}

All reagents except the peptides and the pyridinium salts were obtained from Aldrich Chemie (Bornem, Belgium), and used without further purification. Their concentration was $0.05 \mathrm{M}$, except as otherwise noted. $p$-Toluenesulfonic acid (PTSA) concentration was kept at $0.1 \mathrm{M}$, except as otherwise noted. Peptides were provided by SERVA (Polylab, Antwerpen, Belgium).

Substituted benzylpyridinium bromides were synthesized in our laboratory [24]. Substituted benzylbromide $(0.01 \mathrm{~mol})$ was added to an excess of dry pyridine ( $15 \mathrm{~mL}$ ). Solid benzylbromides were previously dissolved in $3 \mathrm{~mL}$ of dry nitromethane. The mixture was stirred at room temperature for $12 \mathrm{~h}$. Precipitation was induced by the addition of dry diethylether ( 30 $\mathrm{mL}$ ). The precipitate was filtered and rinsed with dry ether. 1-Methylpyridinium iodide was synthesized in the same way from methyliodide.

Solvents were vacuum distilled prior to use. Polydisperse polyethyleneglycol (average molecular weight 300) was also used as a matrix.

\section{Results and Discussion}

The starting point of this study was the observation of a high-intensity peak due to the [solute + glycerol + $\left.\mathrm{H}-\mathrm{II}_{2} \mathrm{O}\right]^{+}$cluster when molecules, including an aldehydic functional group, were analyzed in LSIMS/FAB experiments (the glycerol matrix contained PTSA additive at $0.1 \mathrm{M}$ ). This peak may be the base peak of the recorded spectra, whereas the corresponding [solute + glycerol $+\mathrm{H}]^{+}$signal is often weak or missing. This condensation is often observed to a lesser extent when nonacidified glycerol is used. The effect of acidic additives is discussed below.

This type of reaction is well known in organic chemistry. Ketones and aldehydes react reversibly with alcohols in the presence of acid catalyst to yield acetals. Acidic conditions promote the protonation of the nucleophilic oxygen, and addition of alcohol therefore occurs more rapidly [23].

Acetal formation between substituted benzaldehydes and glycerol occurs widely in LSIMS /FAB mass spectrometry (Table 1). An acetal peak is observed at the first scan, even though organic synthesis of acetal from benzaldehyde and glycerol $\left(\mathrm{H}_{2} \mathrm{SO}_{4}\right.$ catalyst) needs an 8-h heating at $100{ }^{\circ} \mathrm{C}$ to obtain a yield of $39 \%$ [25]. Rapid condensation is therefore believed to be beam induced in the mass spectrometer source.

\section{Structure of the \\ [Solute + Glycerol $\left.+\mathrm{H}-\mathrm{H}_{2} \mathrm{O}\right]^{+}$Cluster}

There are three possible structures for the condensation product formed from $p$-dimethylaminobenzaldehyde and glycerol: the linear form (1), the fivemembered cyclic form (2) and the six-membered cyclic form (3). Various experiments were performed to determine the actual structure.

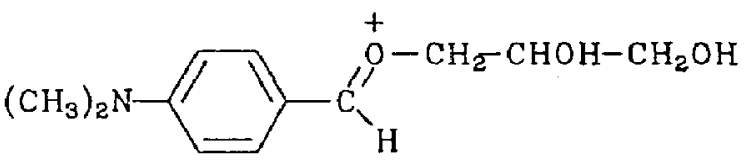


<smiles>CN(C)c1ccc(C2OCC(C=O)O2)cc1</smiles>

2<smiles>CN(C)c1ccc(C2OCC(O)C[OH+]2)cc1</smiles>

3

As previously mentioned, acetal formation between benzaldehydes and glycerol (acid catalyst) is also encountered in organic synthesis. In such a case, the product obtained is a mixture of five- and sixmembered cyclic benzylideneglycerol acetals [25, 26] in which the five-membered cyclic acetal (2) predominates. With a catalytic amount of acid, a slow equilibrium is established between these two isomers with the following equilibrium constant,

$$
K=\frac{\text { Six-membered cyclic acetal concentration }}{\text { Five-membered cyclic acetal concentration }}
$$

in the 0.114-0.119 range [27]. A mechanism for acidcatalyzed five-membered acetal formation from parasubstituted benzaldehyde and glycerol is proposed in Scheme I.

Solvent condensation with loss of a water molecule also occurs when the matrix is thioglycerol. Normal spectra of $p$-dimethylaminobenzaldehyde ( $p$-DMABA) in thioglycerol exhibit in addition to the protonated molecular ion ( $m / z 150)$, a peak due to the corresponding protonated thioaldehyde ( $m / z$ 166) (Figure 1). A solution of $p$-DMABA $(0.05 \mathrm{M})$ in thioglycerol (PTSA additive $0.01 \mathrm{M}$ ) has also been analyzed by MS/MS. Daughter ion scans of the [ $p$-DMABA + thioglycerol $\left.+\mathrm{H}-\mathrm{H}_{2} \mathrm{O}\right]^{+}$species $(m / z$ 240), performed with a triple-stage quadrupole, also show the thioaldehyde (Figure 2). The base peak of this spec-

Table 1. Relative intensities (\%) of the quasimolecular ion and the condensed products of various species of solute molecules (M)

\begin{tabular}{|c|c|c|c|}
\hline Aldehydes and ketones (PTSA) & {$[\mathrm{M}+\mathrm{H}]^{+}$} & {$\left[\mathrm{M}+\mathrm{G}+\mathrm{H}-\mathrm{H}_{2} \mathrm{O}\right]^{+}$} & {$[\mathrm{M}+\mathrm{G}+\mathrm{H}]^{+}$} \\
\hline$p$-OH propiophenone & 48 & 49 & $\mathbf{3}$ \\
\hline$p$-OH acetophenone & 41 & 55 & 4 \\
\hline$p$-Cl benzaldehyde & 33 & 67 & 0 \\
\hline p-OH benzaldehyde & 26 & 73 & 1 \\
\hline$p-\mathrm{OCH}_{3}$ benzaldehyde & 23 & 77 & 0 \\
\hline 3,4- $\mathrm{OCH}_{3}$ benzaldehyde & 19 & 81 & o \\
\hline$p$-DMABA & 8 & 92 & 0 \\
\hline Aldehydes and ketones (no PTSA) & {$\left[\mathrm{M}+\mathrm{HI}^{+}\right.$} & {$\left[\mathrm{M}+\mathrm{G}+\mathrm{H}-\mathrm{H}_{2} \mathrm{O}\right]^{+}$} & {$[M+G+H]^{+}$} \\
\hline$p$-OH propiophenone & 82 & 0 & 18 \\
\hline p-OH acetophenone & 75 & 3 & 22 \\
\hline$p-\mathrm{OH}$ benzaldehyde & 60 & 18 & 22 \\
\hline$\rho-\mathrm{OCH}_{3}$ benzaldehyde & 25 & 75 & 0 \\
\hline $3,4-\mathrm{OCH}_{3}$ benzaldehyde & 20 & 80 & 0 \\
\hline$p$-DMABA & 17 & 83 & 0 \\
\hline Dialdehyde (PTSA) & {$[\mathrm{M}+\mathrm{H}]^{+}$} & {$\left[\mathrm{M}+2 \mathrm{G}+\mathrm{H}-2 \mathrm{H}_{2} \mathrm{O}\right]^{+}$} & {$[M+2 G+H]^{+}$} \\
\hline Terephtalaldehyde & 3 & 62 & 7 \\
\hline Thioketone (PTSA) & {$[\mathrm{M}+\mathrm{H}]^{+}$} & {$\left[\mathrm{M}+\mathrm{G}+\mathrm{H}-\mathrm{H}_{2} \mathrm{~S}\right]^{+}$} & {$\left[\mathrm{M}+\mathrm{G}+\mathrm{H}-\mathrm{H}_{2} \mathrm{O}\right]^{+}$} \\
\hline 4,4'-Dimet hoxythiobenzophenone & 13 & 18 & 2 \\
\hline Arsineoxide (PTSA) & {$[\mathrm{M}+\mathrm{H}]^{+}$} & {$\left[\mathrm{M}+\mathrm{G}+\mathrm{H}-\mathrm{H}_{2} \mathrm{O}\right]^{+}$} & {$[\mathrm{M}+\mathrm{G}+\mathrm{H}]^{+}$} \\
\hline Trimethylarsineoxide & 65 & 31 & 4 \\
\hline Peptides (PTSA) & {$[\mathbf{M}+\mathbf{H}]^{+}$} & {$\left[\mathrm{M}+\mathrm{G}+\mathrm{H}-\mathrm{H}_{2} \mathrm{O}\right]^{+}$} & {$[M+G+H]^{+}$} \\
\hline Tyr -Gly & 90 & 3 & 8 \\
\hline Tyr-Gly-Gly & 90 & 5 & 5 \\
\hline Gly-Gly-Pro-Ala & 91 & 6 & 3 \\
\hline Tyr-Gly-Gly-Phe-Leu & 94 & 5 & 1 \\
\hline Dynorphyn & 94 & 5 & 1 \\
\hline Sar-1.Ala-8 Angiotensin & 94 & 5 & 1 \\
\hline Sar-1,Gly-8 Angiotensin & 97 & 2 & 1 \\
\hline
\end{tabular}

The intensity sum of these ions is taken as $100 \%$.

${ }^{\prime}{ }^{*}$ denotes $4,4^{\prime}$-dimethoxybenzophenone. 
<smiles></smiles><smiles></smiles>
protonated<smiles>[R]c1ccc(C([OH2+])OCC(O)CO)cc1</smiles><smiles>[R]c1ccc(C2OCC(CO)O2)cc1</smiles>
protonated ecetal

Scheme I. Mechanism of the acid-catalyzed, five-membered cyclic deetal formation from para-substiluled benzaldehyde and glycerol (G).

trum $(m / z 134)$ is due to $\left[p \text {-DMABA }-\mathrm{CH}_{4}+\mathrm{H}\right]^{+}$. The same process is observed when the solute is $p$ hydroxybenzaldehyde.

A mechanism for oxygen/sulfur substitution is suggested in Scheme II. It involves a five-membered cyclic acetal, but a six-membered cyclic isomer can also act as an appropriate intermediary; however, this oxygen/sulfur substitution seems unlikely to occur with the linear form. These experiments demonstrate that although the condensation product does not have a unique linear structure, this linear structure cannot be precluded as a component of a mix.

In solution organic chemistry, compound A (Scheme II) can also be synthesized from the corresponding aldehyde and thioglycerol (acid catalysis), but the acidic hydrolysis of compound $A$ yields only an aldehyde. The oxygen atom of this "new" aldehydic functional group comes from the water molecule during the acidic hydrolysis step $[23,28]$. The oxygen/sulfur substitution does not occur in solution organic chemistry.

This oxygen/sulfur substitution is also observed when the aldehyde ( $p$-hydroxybenzaldehyde $=\mathbf{M}$ ) is

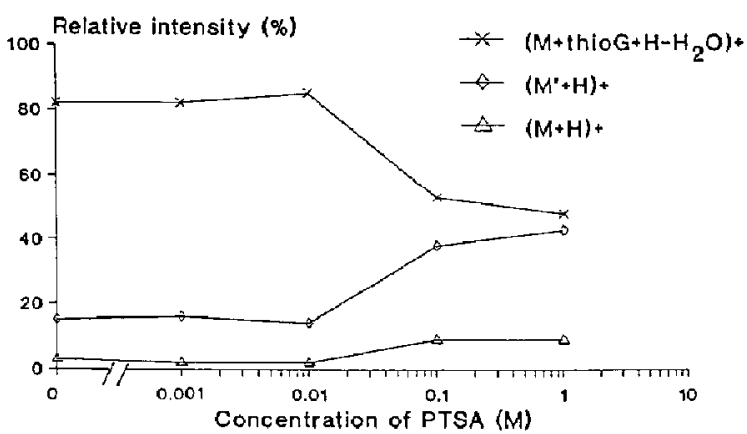

Figure 1. Influence of the concentration of PTSA on the relative intensity of characteristic ions of $p$-DMABA (M) in a thioglycerol (thioG) matrix. The intensity sum of these ions is taken as $100 \%$; $\mathbf{M}^{\prime}$ denotes $p$-dimethylaminothiobenzaldehyde.

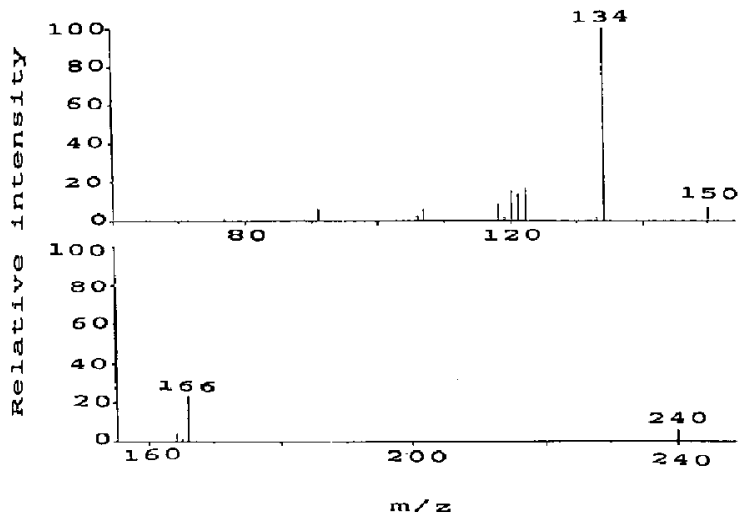

Figure 2. Daughter ion spectrum of the [ $p$-DMABA + thioglycerol $\left.+\mathrm{H}-\mathrm{H}_{2} \mathrm{O}\right]^{+}$species $(m / z 240)$.

mass analyzed in a 1-mercapto-2-propanol matrix (PTSA additive $0.1 \mathrm{M}$ ). The relative intensities of the $\mathrm{MH}^{+}, \mathrm{M}^{\prime} \mathrm{H}^{+},\left[\mathrm{M}+\text { matrix }+\mathrm{H}-\mathrm{H}_{2} \mathrm{O}\right]^{+}$, and $\left[\mathrm{M}^{\prime}+\right.$ matrix $\left.+\mathrm{H}-\mathrm{H}_{2} \mathrm{O}\right]^{+}$species are, respectively, $11 \%$, $19 \%, 65 \%$, and $4 \%$ (where $\mathrm{M}^{\prime}$ denotes the $p$-hydroxythiobenzaldehyde). The signals of the $[\mathrm{M}+$ matrix + $\mathrm{H}^{+}$and $\left[\mathrm{M}^{\prime}+\text { matrix }+\mathrm{H}\right]^{+}$species are insignificant $(<1 \%)$. The intensity sum of all of these ions is taken as $100 \%$. This experiment can only be demonstrated by means of a five-membered cyclic intermediary. Unfortunately, the 1-mercapto-3-propanol is not commercially available; however, it will be synthesized in our laboratory in the near future and will provide a test of the rule of the six-membered ring intermediary.

Daughter ion spectra of acetal species have been produced with a triple-stage quadrupole mass spectrometry, but they do not provide additional structural<smiles>[R]c1ccc(C=[NiH2])cc1</smiles>
thioglycerol ,

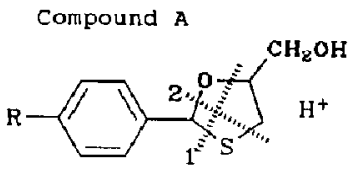<smiles>[R]c1ccc(C(=O)[CH+][PH2+])cc1</smiles>

Scheme II. Oxygen/sulfur substitution mechanism. 
information. Comparison between daughter ion spectra of beam-induced acetals formed from p-hydroxybenzaldehyde, on the one hand, and glycerol, 1,2propanediol, or 1,3-propanediol, on the other, is not structurally helpful because the main fragment of the protonated acetal species is the protonated molecular ion [ $p$-hydroxybenzaldehyde $+\mathrm{H}]^{+}$. 1,2-Propanediol and 1,3-propanediol were chosen because the first species could only generate the linear and/or the five-membered cyclic acetal, and the second species could only give rise to the linear and/or the six-membered cyclic form; however, the intensities of mass-intermediary fragments (i.e., between the parent acetal species and the protonated molecular ion) are weak and cannot be used to characterize the structure of the acetal.

Furthermore, a commercially available five-membered cyclic acetal (acetone ketal of glycerol) was analyzed by MS/MS. The main daughter fragment is due to the [acetone $+\mathrm{H}]^{+}$ion, exactly as for acetals formed in the mass spectrometer.

Until now, no irrefutable evidence has been found to establish the actual structure of these beam-induced acetals; however, compared with the acid-catalyzed classical reaction, these experiments make likely the assumption of the formation of a mixture of two isomeric five- and six-membered cyclic species in which the first one predominates.

Condensation of polyethyleneglycol on aldehydic functional groups with the loss of a water molecule also occurs in a polydisperse polyethyleneglycol matrix (PEG 300). The data for the reaction with p-hydroxybenzaldehyde are listed in Table 2. All of the components of a PEG mixture (from triethyleneglycol to decaethyleneglycol) undergo this reaction in acidic conditions (PTSA additive 0.1 M). The intensity sum of the [solute $+\mathrm{H}^{+}$ion and the acetal peaks are taken as $100 \%$. No signal due to [solute + PEG $+\mathrm{H}^{+}$is detected. PEG is an $\alpha, \omega$-diol requiring very large rings to form cyclic aretals. The difficulty in forming such large rings (entropic factor) seems to make the production of

Table 2. Relative intensities of the quasimolecular ion and the condensed products of $p$-hydroxybenzaldehyde $(\mathrm{M})^{\mathrm{a}}$

\begin{tabular}{lc}
\hline lons $^{b}$ & $\begin{array}{c}\text { Aelative } \\
\text { intensity (\%) }\end{array}$ \\
\hline \hline$[\mathrm{M}+\mathrm{H}]^{+}$ & 5 \\
{$\left[\mathrm{M}+\mathrm{H}+\right.$ triEG $-\mathrm{H}_{2} \mathrm{O}^{+}$} & 2 \\
{$\left[\mathrm{M}+\mathrm{H}+\text { tetraEG }-\mathrm{H}_{2} \mathrm{O}\right]^{+}$} & 11 \\
{$\left[\mathrm{M}+\mathrm{H}+\text { pentaEG }-\mathrm{H}_{2} \mathrm{O}\right]^{+}$} & 20 \\
{$\left[\mathrm{M}+\mathrm{H}+\text { hexaEG }-\mathrm{H}_{2} \mathrm{O}\right]^{+}$} & 23 \\
{$\left[\mathrm{M}+\mathrm{H}+\right.$ heptaEG $-\mathrm{H}_{2} \mathrm{O}^{+}$} & 21 \\
{$\left[\mathrm{M}+\mathrm{H}+\text { octaEG }-\mathrm{H}_{2} \mathrm{O}\right]^{+}$} & 11 \\
{$\left[\mathrm{M}+\mathrm{H}+\text { nonaEG }-\mathrm{H}_{2} \mathrm{O}\right]^{+}$} & 5 \\
{$\left[\mathrm{M}+\mathrm{H}+\text { decaEG }-\mathrm{H}_{2} \mathrm{O}\right]^{+}$} & 2 \\
\hline
\end{tabular}

a PEG 300 matrix with PTSA additive; the intensity sum of all these ions is taken as $100 \%$.

${ }^{\circ} \mathrm{EG}$, ethyleneglycol. a linear acetal in this case probable. The structure of this acetal will be examined in a subsequent study.

\section{Influence of Acidic Additives}

The effect of acidity was studied through the use of two types of acids: (1) a simple mineral acid (phosphoric acid); and (2) an organic acid with surfactant properties (PTSA). The addition of phosphoric acid has three major consequences: (1) The $\mathrm{pH}$ of the solution is decreased; (2) the solubilization of the analyte is improved; and (3) the concentration of preformed ions in solution is increased. The choice of phosphoric acid is based on its low volatility. The relative intensity of the acetal peak increases when the concentration of phosphoric acid is increased (Figure 3a). This effect is observed for both $p$-hydroxybenzaldehyde and $p$ DMABA (two separate solutions); however, an optimum phosphoric acid concentration exists and lies in the $0.1 \mathrm{M}$ range.

Exactly the same behavior is observed when the acidic additive is PTSA (Figure $3 b$ ). The optimum PTSA concentration also lies in the $0.1 \mathrm{M}$ range. The
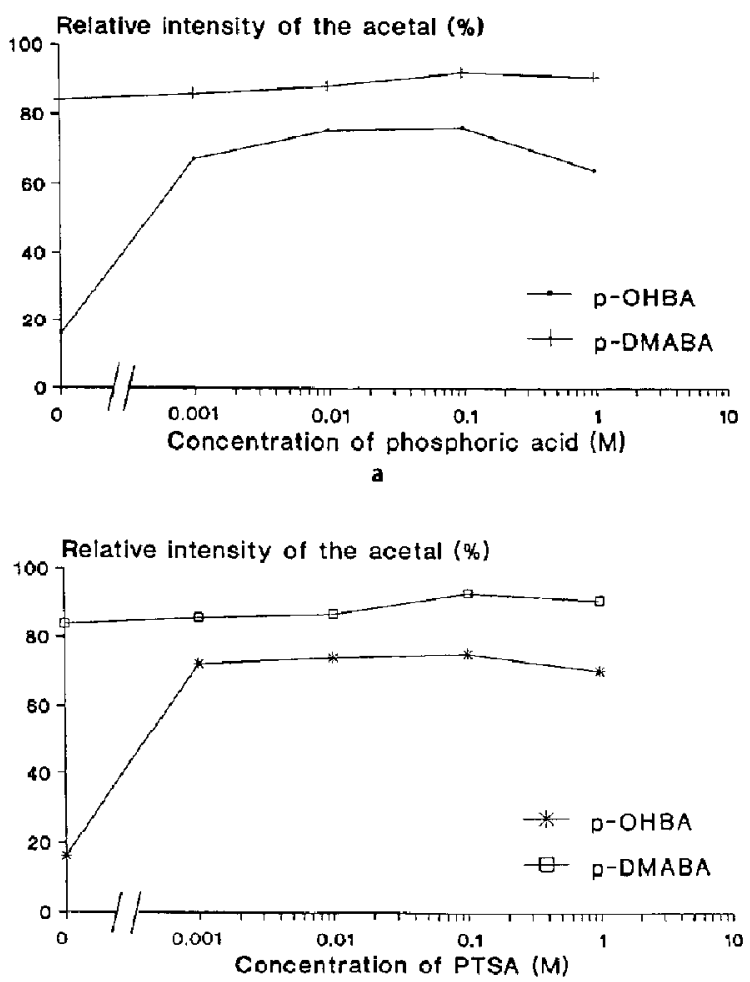

b

Figure 3. Influence of the concentration of acidic additives on the relative intensity of the acetal ion species. Two solutes were examined (separately): $p$-hydroxybenzaldehyde ( $p$-OHBA) and $p$-DMABA in glycerol $(\mathrm{G})$. The intensity sum of the [solute $+\mathrm{H}]^{+}$, Isolute $+\mathrm{G}+\mathrm{H}-\mathrm{H}_{2} \mathrm{O}^{+}$(acetal ion), and [solute $\left.+\mathrm{G}+\mathrm{H}\right]^{+}$ was taken as $100 \%$. (a) $\mathrm{H}_{3} \mathrm{PO}_{4}$ additive; (2) PTSA additive. 
comparison between these experiments points out that the acidity of the solution is important in these cases. The relative influence of acid depends on the nature of the aldehyde (see also Table 1).

Although the effect of phosphoric acid and PTSA on the relative intensity of the condensed product is the same, the use of a surfactant acid is more favorable because this additive promotes the surface migration of analyte ions; for example, the [glycerol $+\mathrm{H}]^{+} /[p-$ DMABA $+\mathrm{H}]^{+}$ratio is equal to 3 when no additive is used; to 10 when $\mathrm{H}_{3} \mathrm{PO}_{4}(0.1 \mathrm{M})$ is added; and to $1 \mathrm{in}$ the case of PTSA (0.1 M). The use of PTSA additive increases the signal:background ratio. In addition, PTSA itself produces little signal in the mass spectrum, but phosphoric acid induces interfering $\left[\mathrm{H}_{3} \mathrm{PO}_{4}\right]_{n} \mathrm{H}^{\prime}$ peaks $(n=1-5)$ and mixed clusters with glycerol.

Analysis of the influence of the concentration of PTSA on the relative intensity of the acetal species was performed in the case of a thioglycerol matrix (Figure 1). The optimum concentration lies in the $0.01 \mathrm{M}$ range. This lower value can be caused by the greater acidity of thioglycerol $\left(\mathrm{p} K_{\mathrm{a}}<10\right)$ relative to glycerol $\left(\mathrm{p} K_{\mathrm{a}} 14\right)$.

It is noteworthy that in solution organic chemistry, a high acid concentration decreases the yield of acetal because of the promotion of reverse acidic hydrolysis.

\section{Influence of Solute Type}

Various species of analyte molecules undergo this condensation process. The molecules tested are considered herein according to their chemical nature.

Benzaldehydes. The type of substituent attached to the benzaldehyde has an influence on the extent of acetal formation. The electron-donating or electronwithdrawing characteristics must be taken into account.

The relative intensities of the protonated molecular ion and the [solute + glycerol $\left.+\mathrm{H}-\mathrm{H}_{2} \mathrm{O}\right]^{+}$and [solute + glycerol $+\mathrm{H}]^{+}$species signals of various benzaldehydes with and without PTSA (0.1 M) are listed in Table 1 (no signal related to the analyte is observed for $p-\mathrm{Cl}$ benzaldehyde when PTSA is not added to the glycerol matrix). The intensity sum of these ionic signals is taken as $100 \%$. $\Lambda$ substituent effect can be pointed out. The same substituent effect is observed in organic chemistry: The reaction rate correlates with the electron-donating ability of the para-substituent [29].

Dialdenyde. When the analyte includes two aldehydic groups, two glycerol molecules condense on the dialdehyde, and a two-water-molecule loss accompanies the process. The example of the terephtalaldehyde is given in Table 1 .

Ketones. Solvent condensation with the loss of a water molecule is less intense with ketones (see Table 1).
This effect is probably due to both steric and electronic reasons because aldehydes are generally more reactive than ketones in nucleophilic addition reactions.

Thioketones. Thioketones also undergo solvent condensation with the loss of an $\mathrm{H}_{2} \mathrm{~S}$ molecule. In organic chemistry, thioketones are more reactive than ketones because the $\mathrm{H}_{2} \mathrm{~S}$ molecule is a better leaving species than the $\mathrm{H}_{2} \mathrm{O}$ molecule. In the case of aldehydes and ketones, an oxygen-18 study of acetal formation established that the oxygen atom lost in forming the water molecule comes from the carbonyl group [28].

The mass spectrum of 4,4'-dimethoxythiobenzophenone (M) in glycerol (G) açidified with PTSA (0.1 M) (see Table 1) exhibits two interesting points: (1) formation of $\mathrm{a}\left[\mathrm{M}+\mathrm{G}+\mathrm{H}-\mathrm{H}_{2} \mathrm{~S}\right]^{+}$cluster; and (2) substitution between sulfur and oxygen atoms-a peak corresponding to the protonated 4,4'-dimethoxybenzophenone $\left[\mathrm{M}^{\prime}+\mathrm{H}\right]^{\prime}$ signal is observed and is far more intense than the protonated molecular one. This process can induce an erroneous interpretation of the spectrum. The $\left[\mathrm{M}^{\prime}+\mathrm{H}\right]^{+}$ion might be considered a fragment of the $[\mathrm{M}+\mathrm{H}]^{+}$ion, but its absence in the daughter ion spectra of the quasimolecular species $[\mathrm{M}+\mathrm{H}]^{+}$invalidates this assumption.

The peak at $317 \mathrm{u}$ fits both $\left[\mathrm{M}+\mathrm{G}+\mathrm{H}-\mathrm{H}_{2} \mathrm{~S}\right]$ and $\left[\mathrm{M}^{\prime}+\mathrm{G}+\mathrm{H}-\mathrm{H}_{2} \mathrm{O}\right]^{+}$clusters, but the latter possibility is unlikely as a unique form because the sulfur/oxygen substitution presupposes a prior acetal formation from thioketone.

\section{Other Compounds}

Arsine oxide. Cesium ion bombardment of a glycerolic solution of trimethylarsine oxide $\left[\mathrm{M}:\left(\mathrm{CH}_{3}\right)_{3} \mathrm{AsO}\right]$ (PTSA additive $0.1 \mathrm{M}$ ) also gives rise to a secondary reaction (Table 1 ).

Peptides. All of the tested peptides [Tyr-Gly, Tyr-Gly-Gly, Tyr-Gly-Gly-Phe-Leu (leucine enkephalin), Gly-Gly-Pro-Ala, dynorphin, (Sar-1, Gly-8) angiotensin $\mathrm{II}$, and (Sar-1, Ala-8) angiotensin II] undergo solvent condensation with the loss of a water molecule (Table 1). This secondary reaction occurs to a lesser extent relative to the other types of analyte molecules. In this case, the condensation product should be the result of an esterification reaction (reaction between the terminal carboxylic acid functional group of the peptide and an alcoliol functional group of glycerol) [30]. This type of reaction is illustrated as follows:

$$
\begin{array}{r}
\mathrm{R}-\mathrm{COOH}+\mathrm{HOCH}_{2}-\mathrm{CHOH}-\mathrm{CH}_{2} \mathrm{OH} \stackrel{\mathrm{H}^{+}}{\longrightarrow} \\
\mathrm{R}-\mathrm{COOCH}_{2}-\mathrm{CHOH}-\mathrm{CH}_{2} \mathrm{OH}+\mathrm{H}_{2} \mathrm{O}
\end{array}
$$

The mass spectrum exhibits a signal corresponding to [solute $\left.+\mathrm{G}+\mathrm{H}-\mathrm{H}_{2} \mathrm{O}\right]^{+}$, but the structure of this species is different from the condensation product formed from aldehydes, ketones, and thioketones. In 
the case of peptides, no acetal condensation product is likely to be formed.

\section{How This Matrix Effect Is Used in LSIMS/FAB Mass Spectrometry Analysis}

Metastable protonated acetal ions [solute + solvent + $\left.\mathrm{H}-\mathrm{H}_{2} \mathrm{O}\right]^{+}$formed in the mass spectrometer source decompose in the 1-FFR giving mainly the quasimolecular ion [solute $+\mathrm{H}^{+}$. CAD gives the same result (see Structure of the [Solute + Glycerol $\left.+\mathrm{H}-\mathrm{H}_{2} \mathrm{O}\right]^{+}$ Cluster). This suggests that mass spectrometric analysis could take advantage of the reversibility of this condensation through MS/MS experiments.

Constant neutral loss scans can be run to monitor a selected neutral molecule loss associated with given chcmical groups. For example, a scan monitoring neutral loss of $74 \mathrm{Da}\left[\mathrm{G}-\mathrm{H}_{2} \mathrm{O}\right]$ (i.e., the mass difference between the observed [solute $+\mathrm{G}+\mathrm{H}-\mathrm{H}_{2} \mathrm{O}{ }^{+}$and [solute $+\mathrm{H}^{+}$species) performed on a sample containing molecules undergoing solvent condensation with a water molecule loss exhibits a peak due to the protonated acetal (the precursor mass is labeled on the MS/MS neutral loss spectra). Such a linked scan could be used to select specific families of compounds in complex mixtures.

Normal and constant neutral loss scans were compared for several mixtures. These spectra were analyzed with a VG Autospec-Q testing for neutral loss in the 1-FFR without collision gas. The composition of four mixtures is as follows. Mixfure 1 consisted of 3,4-dimethoxybenzaldehyde $\left(\mathrm{MH}^{+}: m / z \quad 167\right) ; 4^{\prime}$ hydroxypropiophenone $\left(\mathrm{MH}^{+}: m / z\right.$ 151); and crystal violet $\left(\mathrm{M}^{+}: m / z 372\right)$ in a glycerol matrix (PTSA additive). Mixture $1^{\prime}$ contained the same components as mixture 1, but the matrix was thioglycerol (PTSA additive). Mixture 2 included $p$-DMABA $\left(\mathrm{MH}^{+}: m / z\right.$ 150); p-hydroxybenzaldehyde $\left(\mathrm{MH}^{+}: m / z\right.$ 123); pyridine $\left(\mathrm{MH}^{+}: m / z\right.$ 80); 1-phenylethylpyridinium bromide $\left(\mathrm{M}^{+}: m / z\right.$ 184); and $p$-Br 1-benzylpyridinium bromide $\left(\mathrm{M}^{+}: m / z 248\right)$ in a glycerol matrix (PTSA additive). Mixture 2' contained the same components as mixture 2, but the matrix was thioglycerol (PTSA additive).

All of the components of the samples had the same concentration $(0.05 \mathrm{M})$. The concentration of the PTSA additive was $0.05 \mathrm{M}$ in glyccrol and $0.01 \mathrm{M}$ in thioglycerol (see Influence of Acidic Additives). Some components were specially chosen because of their surfactant properties in such a way as to suppress, in normal scan spectra, the signal from other components that underwent condensation. Table 1 confirms that the spectra of condensable components alone exhibit target ions in the absence of surfactant-induced suppression.

The LSI mass spectrum of mixture 1 in glycerol (Figure 4a) illustrates the surface-active character of crystal violet cations. Crystal violet is a hydrophobic triphenyl methane dye with no carbonyl. A daughter ion mass spectrum of the crystal violet molecular cation establishes that all of the major peaks observed in
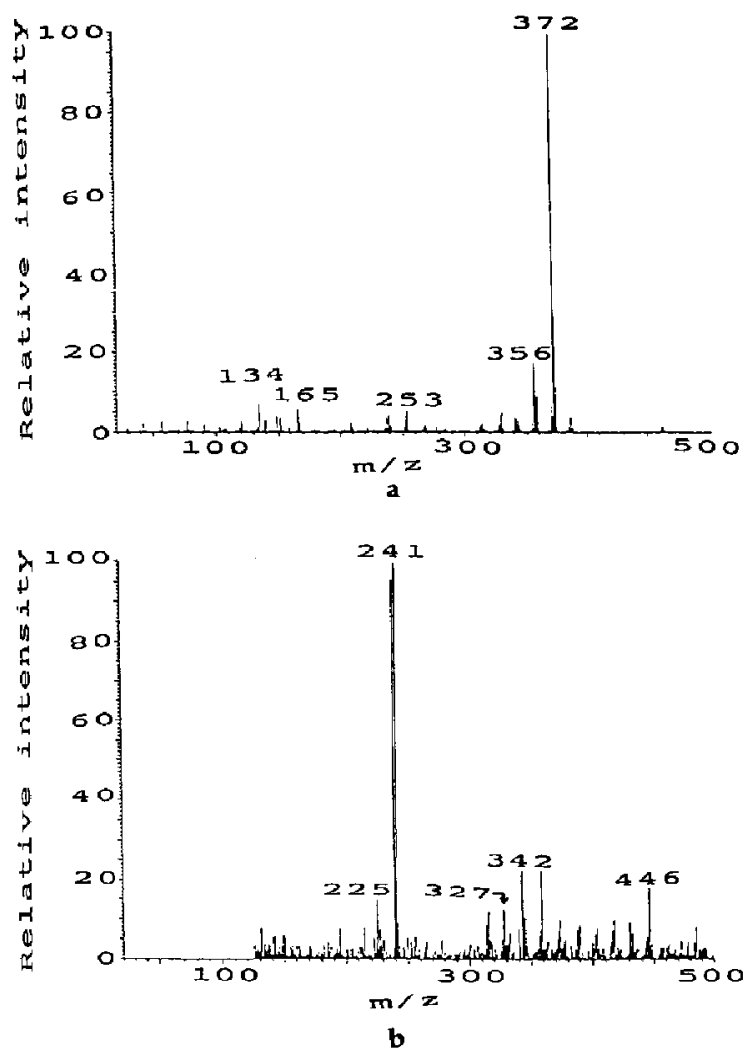

Figure 4. Mass spectra of mixture 1 in a glycerol matrix (PTSA additive). (a) Normal mass spectrum; (b) 74-Da constant neutral loss spectrum.

Figure $4 \mathrm{a}$ are related to the crystal violet cation and its fragments. Quasimolecular ions of the aldehyde and ketone components give rise to low-intensity peaks, and no acetal ion peaks are observed in Figure 4a.

Figure $4 \mathrm{~b}$ shows that the neutral loss scan (loss of 74 Da) can be used as a screening tool, even when one component of the mixture is so surface active that the signals of other reactive components have low intensities; the neutral loss scan highlights the reactive molecules of the sample. The $[\mathrm{X}+74]^{+} \rightarrow \mathrm{X}^{+}$ metastable transition is observed when $X$ denotes the protonated aldehyde or the protonated ketone, giving rise to signals at $m / z 241$ and 225, respectively; but it also occurs when $X$ is taken as the crystal violet cation $(m / z 446)$ or ils iragments $(m / z 358,342$, and 327 notably). Clusters are formed between the crystal violet molecular and fragment cations, on the one hand, and $\left[\mathrm{G}-\mathrm{H}_{2} \mathrm{O}\right]$, on the other. These clusters are not observed above background during a normal magnet scan, but they are accentuated in neutral loss scan experiments.

In mixture 2, the two pyridinium salts are so surface active that the two aldehydes are excluded from the surface, and the signals related to these aldehydes are fairly weak or missing in LSI mass spectrum (Fig- 
ure 5a). The $\alpha$-methylbenzylium ion $(m / z 105)$ is the only fragment of the phenylethylpyridinium ion, and the $p$ - $\mathrm{Br}$ benzylium ion $(m / z 169$ ) is the only fragment of the $p$-Br 1-benzylpyridinium ion. Linked scan experiments (neutral loss of $74 \mathrm{Da}$ ) performed with the same mixture exhibit prominent peaks corresponding to $\left[p \text {-DMABA }+\mathrm{H}+\mathrm{G}-\mathrm{H}_{2} \mathrm{O}\right]^{+}(m / z 224)$, $\left[p \text {-DMABA }-\mathrm{CH}_{4}+\mathrm{H}+\mathrm{G}-\mathrm{H}_{2} \mathrm{O}\right]^{+}(m / z 208)$, and [ $p$-hydroxybenzaldehyde $\left.+\mathrm{H}+\mathrm{G}-\mathrm{H}_{2} \mathrm{O}\right]^{+}$ ( $m / z$ 197) (Figure 5b); however, clusters between the fragments of pyridinium salts and dehydrated glycerol molecules are also observed in the neutral loss mass spectrum ( $m / z 179$ and 243 ) (Figure $5 b$ ), but they are not evident above background in the normal spectrum (Figure 5a). Clusters, including molecular pyridinium cations and dehydrated glycerol molecules, are not observed in any of these spectra. It seems noteworthy that there are both pyridinium ions ( $m / z 248$ and 184) and their fragments $(m / z 169$ and 105) in Figure 5a but only fragment adducts in Figure 5b. This appears contrary to the expectation that solvation should mitigate fragmentation. These features have been confirmed with other pyridinium salts (1-diphenylmethylpyridinium bromide and 1-methylpyridinium iodide).
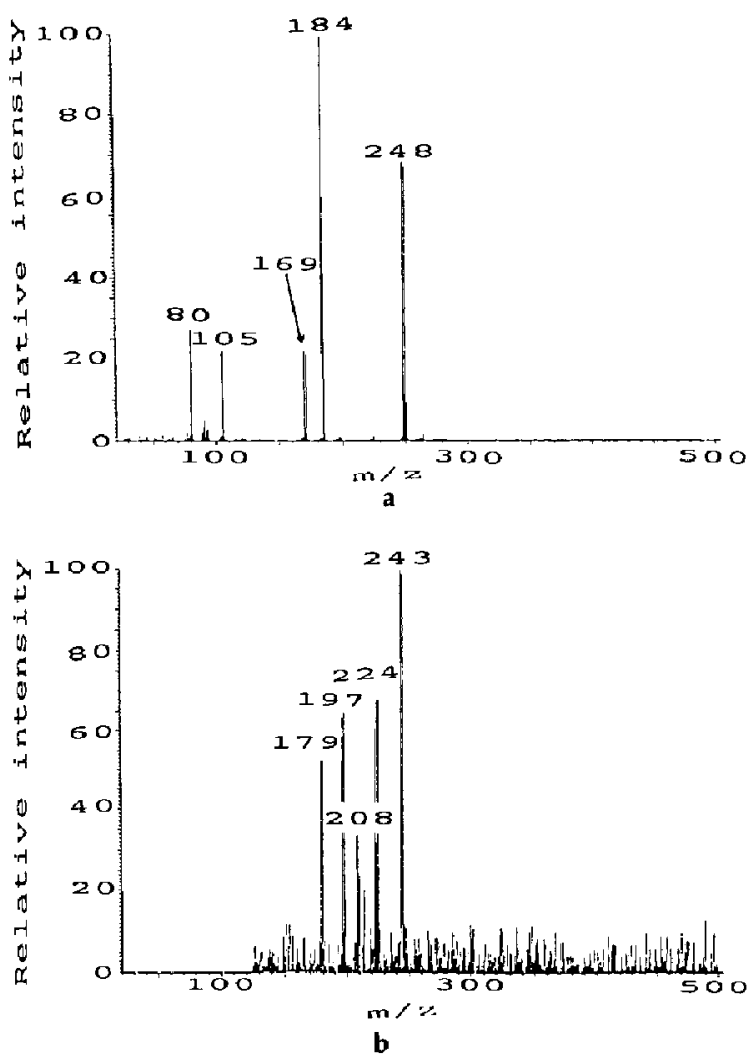

Figure 5. Mass spectra of mixture 2 in a glycerol matrix (PTSA additive). (a) Normal mass spectrum; (b) 74-Da constant neutral loss spectrum.
These experiments were repeated using a thioglycerol matrix (with a PTSA concentration of $0.01 \mathrm{M}$ ) instead of glycerol. In this case, the neutral loss mass to be taken into account was $90 \mathrm{Da}$ [thioglycerol $\left.\mathrm{H}_{2} \mathrm{O}\right]$. The LSI mass spectra of mixture $1^{\prime}$ in thioglycerol (Figure 6a) and mixture 1 in glycerol (Figure 4a) are similar; however, linked scans performed with a thioglycerol matrix (Figure 6b) selectively highlight the molecules undergoing acetal formation.

Signals related to the aldehydes are fairly weak or missing in the LSI mass spectrum of mixture $2^{\prime}$ in thioglycerol (Figure 7a). The 90-u loss scan performed with mixture 2' (Figure 7b) is also conclusive for the selection of the molecules undergoing acetal formation. Besides the acetal ion signals, a peak due to [ $p$-DMABA $-\mathrm{CH}_{4}+$ thioglycerol $\left.+\mathrm{H}-\mathrm{H}_{2} \mathrm{O}\right]^{+}$ $(\mathrm{m} / \mathrm{z} 224)$ and a cluster between the protonated pyridine and the [thioglycerol $-\mathrm{H}_{2} \mathrm{O}$ ] species $(m / z 170)$ are also observed. These linked-scan spectra performed with a thioglycerol matrix are very clean and can be used to infer helpful information. Thioglycerol appears to be a better solvent than glycerol for this neutral loss approach to functional group identification. The enhanced fragmentation in Figure 7 a (relative to Figure 5a) is noteworthy, especially in light of the
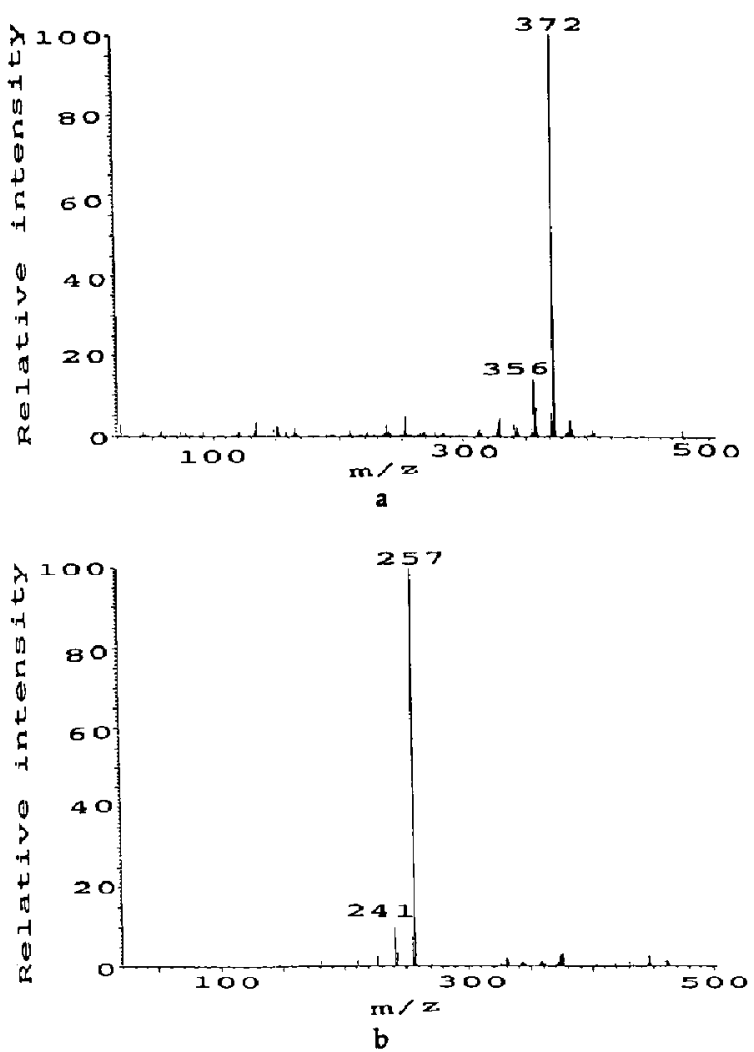

Figure 6. Mass spectra of mixture $1^{\prime}$ in a thioglycerol matrix (PTSA additive). (a) Normal mass spectrum; (b) 90-Da constant neutral loss spectrum. 

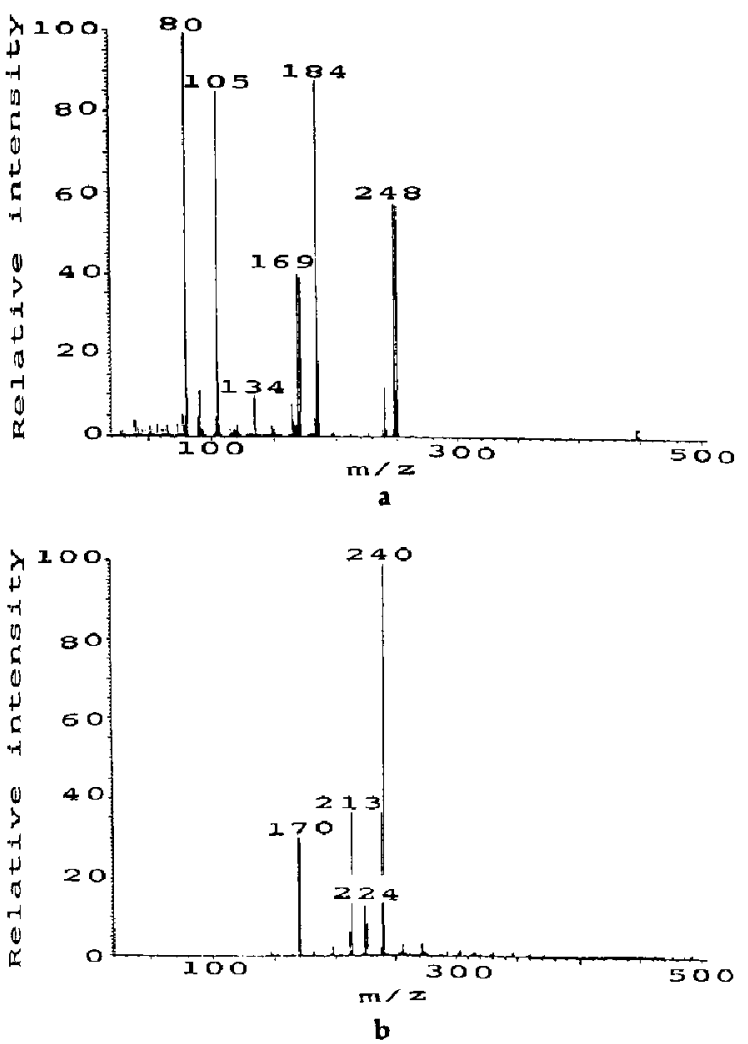

Figure 7. Mass spectra of mixture $2^{\prime}$ in a thioglycerol matrix (PTSA additive). (a) Nurmal mass spectrum; (b) 90-Da constant neutral loss spectrum.

fact that thioglycerol is often alleged to mitigate beam damage [17, 31]. In previous experiments [24], a fragmentation mitigation of the benzylpyridinium ions was observed when PTSA was added to glycerol. The enhanced fragmentation in the thioglycerol matrix could be induced by the lesser surfactant additive concentration. The absence of benzylpyridinium fragments in Figure $7 \mathrm{~b}$ is more remarkable in light of their enhancement in Figure 7a.

Constant neutral loss spectra demonstrate ionic species that could be representative of the chemistry induced by the primary particle. These ions seem to be essentially unstable and mainly decompose in the mass spectrometer source; a fraction of them is metastable and decomposes in the 1-FFR, giving rise to characteristic signals in the constant neutral loss spectra; however, these species are not observed in normal spectra dominated by stable ions. A better understanding of the beam-induced condensation products can be inferred from neutral loss spectra.

\section{Conclusions}

Matrix effects are often considered a severe drawback to the use of a liquid solvent in LSIMS/FAB mass spectrometry because they can induce misinterpretation of mass spectra. Beam-induced artifacts can have an effect on both qualitative and quantitative analysis. In most cases, inhibitors are required to control matrix effects [18].

Nevertheless, advantage can be gained from some types of secondary reactions to infer analytical information. Solvent condensation with loss of a water molecule occurs for several families of analytes, the common character of which seems to be the presence of a double bond, including a heteroatom (oxygen, sulfur).

This study demonstrates a useful application of this matrix effect when the detection of some components of a mixture is prevented by other more surface-active components. Constant neutral loss scans can be used as a screening tool to highlight the reactive molecules of the sample. Specific linked scans performed with thioglycerol are more conclusive than those obtained with a glycerol matrix. Constant neutral loss spectra allow detection of metastable ionic species that could act as intermediaries in the formation of fragment ions.

\section{Acknowledgments}

A. Agnello is grateful to the I.R.S.I.A. for the awarding of a grant. Professor de Hoffmann is gratefully acknowledged for allowing us to obtain triple-stage quadrupole mass spectra. A. Agnello also thanks F. Derwa for providing the pyridinium salts.

\section{References}

1. Barber, M.; Bordoli, R. S.; Elliot, G. J.; Sedgwick, R. D.; Tyler, A. N. Anal. Chem. 1982, 54, 645A-657A.

2. Magee, C. W. Int. J. Mass Spectrom. Ion Fhys. 1983, 49, 211-221.

3. De Pauw, E.; Agnello, A.; Derwa, F. Mass Spectrom. Rev. 1991, 10, 283-301.

4. De Pauw, E. Mass Spectrom. Rev. 1986, 5, 191-212.

5. Cook, K. D.; Todd, P. J.; Friar, D. H. Biomed. Enoiron. Mass Spectrom. 1989, 18, 492-497.

6. Ligon, W. V.; Dorn, S. B. I. Am. Chem. Sac. 1988, 110, 6684-6688.

7. Ligon, W. V. In Proceedings of the Second International Sympositum on Mass Spectrometry in the Health and Life Sciences; San Francisco, CA, 1989.

8. Lehrnan, W. D.; Kessler, M.; Konig, W. A. Biomed. Mass Spectrom. 1984, 11, 217-222.

9. Dass, C.; Desiderio, D. M. Anal. Chem. 1988, 60, 2723-2729.

10. Sethi, S. K.; Nelson, C. C.; McCloskey, J. A. Anal. Chem, 1984, 56, 1975-1977.

11. Keough, T. Int. I. Mass Spectrom. Ion Processes 1988, 86, $155-168$.

12. Divisia-Blohorn, B; Kyriakakou, G.; Ulrich, J. Org. Mass Spectrom. 1985, 20, 463-466.

13. Grotjahn, L.; Ernst, L. Z. Naturforsch. 1984, 39b, 1548-1552.

14. Mallis, L. M: Scott, W. J. Org. Mass Spectrom. 1990, 25, 415-419.

15. Pelzer, G.; De Pauw, E.; Dung, D. V.; Marien, J. J. Phys. Chem, 1984, 88, 5065-5068.

16. Cerny, R. L.; Gross, M. L. Anal Chem. 1985, 57, 1163-1165.

17. Reynolds, J. D.; Cook, K. D. I. Am. Soc. Mass Spectrom. 1990, 1, 149-157. 
18. Agnello, A; De Pauw, E. Org. Mass Spectrom. 1991, 26, 175-177.

19. Emary, W. B.; Cooks, R. G.; Toren, P. C. Anul. Chem. 1986, $58,1218-1221$.

20. De Pauw, E. Spectrosc. Int. J. 1989, 7, 83-90.

21. De Pauw, E. Methods Enzymol. 1990, 193, 201-214.

22. Agnello, A.; Derwa, F.; De Pauw, E. In Proceedings of the N.A.T.O. Advanced Studies Institute on the Formation of Ions from Involatile Molecules; Winnipeg, 1990; pp 117-121.

23. McMurry, J. Organic Chemistry; Brooks and Cole: California, 1984; p 706.

24. Derwa, F. Ph.D. thesis, University of Liege, 1992-1993, III. 31, V. 39.
25. Hill, H. S.; Whelen, M. S.; Hibbert, H. J. Am. Chem. Soc. 1928, $50,2235-2242$.

26. Hill, H. S.; Hibbert, H. I. Am. Chem. Soc. 1923, 45, 3117-3124.

27. Piantadosi, C.; Anderson, C. E.; Brecht, E. A.; Varbo, C. L. J. Am. Chem. Soc. 1958, 80, 6613-6617.

28. Stasiuk, F; Sheppard, W. A; Bourns, A. W. Can I. Chem. 1956, 34, 123-127.

29. Davis, T. S.; Feil, P. D.; Kubbler, D. G.; Wells, D. J. /. Org. Chem. 1975, 40, 1478-1482.

30. McMurry, J. Organic Chemistry; Brooks and Cole: California, $1984 ;$ p 777.

31. Takayama, M.; Fukai, T.; Nomura, T.; Nojima, K. Int. J. Mass Spectrom. Ion Processes, 1990, 96, 169-179. 